\title{
Synthesis and characterization of biodiesel from castor bean as alternative fuel for diesel engine
}

\author{
Molla Asmare*, Nigus Gabbiye \\ Centre of Competence for Sustainable Energy Engineering, Institute of Technology, Bahir Dar University, Bahir Dar, Ethiopia \\ Email address: \\ mollaasmare98@gmail.com (M. Asmare) \\ To cite this article: \\ Molla Asmare, Nigus Gabbiye. Synthesis and Characterization of Biodiesel from Castor Bean as Alternative Fuel for Diesel Engine. \\ American Journal of Energy Engineering. Vol. 2, No. 1, 2014, pp. 1-15. doi: 10.11648/j.ajee.20140201.11
}

\begin{abstract}
This paper deals with the transesterification of Ricinus Communis (RC) oil with methanol to produce biodiesel in the presence of $\mathrm{KOH}$ as a catalyst. Moreover, this study analysis the fuel properties of RC biodiesel and diesel fuel blend to use castor oil methyl ester as a possible alternative fuel for diesel engines. Various properties of the RC biodiesel and their blends such as density, kinematic viscosity, iodine value, saponification number, Cetane number, heating value, flash point and acid value were determined. The experimental results were compared well with American Society for Testing and Materials (ASTM D6751) and European biodiesel standards (EN 14214). The experimental design as well as statistical analysis were done and analyzed using design expert 8.0.7.1 version soft ware. The predicted optimum conditions for castor oil biodiesel production were a reaction temperature of $59.89^{\circ} \mathrm{c}$, methanol to oil ratio of $8.10: 1$ and a catalyst of $1.22 \mathrm{wt} \%$ of oil. The methyl ester content under these optimum conditions was $94.5 \% \mathrm{w} / \mathrm{w}$ of oil, and all of the measured properties of the biodiesel met the international standards of EN14214 and ASTM D 6751 with the exception of density and viscosity. Therefore, the viscosity and density of the ester was high and further reduced by blending with diesel fuel up to B45 to satisfy within the ASTM D6751 and EN 14214 limits for biodiesel.
\end{abstract}

Keywords: Castor Seed, Castor Oil, Biodiesel, Transesterification, Blend, Response Surface Methodology

\section{Introduction}

The developments of societies have accompanied by an increase in growing energy needs. Their energy requirements have achieved through the combustion of various materials (oil, coal and natural gas) which considered as fossil fuels and therefore non-renewable, which creates environmental problems. These facts have converged in the search for renewable energy sources such as Biofuels: a non-toxic, biodegradable, agricultural source, with a high heating value and oxygen content [1].

Global warming is one of the greatest environmental threats facing our planet caused by increasing in atmospheric Green House Gases (GHG) due to human activities since the start of the industrial era [2]. When fuels were burnt, there are just a few basic types of primary exhaust emissions (oxides of nitrogen $\left(\mathrm{NO}_{\mathrm{X}}\right)$, Carbon monoxide (CO), hydrocarbons ( $\mathrm{HC})$, Carbon dioxide $\left(\mathrm{CO}_{2}\right)$ and particulate matter (PM)). In addition to these, primary pollutants reactions in the atmosphere generate secondary pollutants that cause acid rain, photochemical smog and tropospheric ozone depletion. Many of these pollutants have serious implications on human health and the environment. Consequently, many countries have established strict environmental policies and regulations that must meet by all automobile manufacturers.

The search for alternative fuels started when the pollution created by the burning of fossil fuels shows severe environmental problems because biofuels have a significant role in overall reduction of $\mathrm{CO}_{2}$ emissions [3]. Bioethanol is the most well known biofuels used in gasoline engines. Similarly, manufacturers have worked with biodiesel, as it is the most common alternative fuel for traditional diesel engines.

Among the most promising sources, vegetable oils and animal fats have attracted much attention as a potential resource for the production of biodiesel, which is quite similar to conventional diesel in its main characteristics and can be easily blended with diesel fuel in any proportion with minor or no modifications to the engine as well as fuel system [4]. The production and use of biodiesel have increased significantly in many countries around the world 
using numerous feedstock sources. Unfortunately, it is in nascent status in many African countries.

Over the past decade, the consumption of transport fuels in Sub-Saharan Africa has increased at a rate of 7\% per year in line with increased economic activity [5]. This has had a great economic impact on about thirty-five crude oil importing countries in Africa. However, they have large landmass for farming and abundance resource of edible and inedible oils, some of which grow in the wild. This shows that Sub-Saharan African countries are a region with a high potential feedstock for biodiesel production.

Biodiesel is the general name for fatty acid alkyl esters and the most common alternative fuel for traditional diesel engines. It can be produced by transesterification in which oil or fat is reacted with a monohydric alcohol in the presence of appropriate catalyst. To complete a transesterification reaction Stoichiometrically, a 3:1 molar ratio of alcohol to triglycerides (TGs) is necessary. Practically, the ratio needs to be higher to drive the equilibrium to a maximum ester yield. The process of transesterification is affected by the mode of reaction, molar ratio of alcohol to oil, type of alcohol, nature and amount of catalysts, reaction time and temperature.

Several studies have been carried out using different oils, alcohols (methanol, ethanol, isopropanol and butanol) and catalysts, notably homogeneous ones; sodium hydroxide, potassium hydroxide, sulfuric acid and supercritical fluids or enzymes such as lipases [6]. Consequently, a number of reasons for converting oils and fats into biodiesel have been also discussed. Some of the main problems with oils and fats are high viscosity and low volatility that cause the formation of deposits in engines due to incomplete combustion and incorrect vaporization characteristics [7].

Ricinus communis $L(R C)$, which belongs to the family of euphorbiaceous is one of biodiesel feed stock. The bean contains toxin that makes the oil and cake inedible. It grows very well on marginal land, is drought and pest resistant, and has a yield of about 1413 liter per hectare when cultivated. The beans contain $40-60 \%$ oil by weight for high yield breed type. It is one of the highest viscosities among vegetable oils. The oil produced from the seed of the castor plant (Ricinus communis) has stimulated some interest as a biofuels. Its oil coloration ranges from a pale yellow to colorless, and has a soft and faint odor with a highly unpleasant taste. The fatty acids in a castor oil contain a hydroxyl functional group, which cause castor oil to be more polar than other vegetable oils. Since the polarity of castor oil is sufficiently high, the oil mixes completely with methanol during the biodiesel reaction. It is made up of TGs; $91-95 \%$ Ricinoleic acid, 4-5\% Linoleic acid, $2-4 \%$ of oleic acid and 1-2\% Palmitic and Stearic acids. Ricinoleic acid, a monounsaturated, 18-carbon fatty acid, is unusual in that it has a hydroxyl functional group on the twelfth carbon. As a result, the automotive industry uses castor oil for the production of high performance motor oil and braking fluids [8].

Nowadays, all Ethiopian petroleum products imported either through the port of Djibouti or from Sudan. Besides the cost of fuel, long distance transportation adds to the cost of the fuel getting to Addis Ababa that causes a large burden on Ethiopia's trade balance. One main issue is that around $65 \%$ of Ethiopian export earnings are to pay for the import of petroleum products. Despite the availability of huge energy resources, the current level of harnessing this energy is very low. This is due to poor socio-economic situation in the country on the one side, and a low level of awareness about the potential and value of energy by most stakeholders on the other side. Amongst the identified alternative renewable energy sources, biofuels in particular energy crops received attention as a promising and sustainable energy sources, of which, biodiesel has arisen as a potential candidate for a petro diesel substitute that minimize the escalating budgetary pressure for diesel oil.

The development of biodiesel is a recent and at its initial stage in Ethiopia. Ethiopia has ample potential and opportunities for the production and utilization of biodiesel from Jatropha, castor oil, palm oil (edible), and neem instead of petroleum. However, the country did not yet benefited from those biodiesel feedstocks because of educated human power and economical constraints. Among them, Castor bean is a non-edible biodiesel feedstock to substitute the consumption of fossil fuel. In addition, it is widely available and has no any other commercial purpose, has high oil content and yields per hector, grows in marginal land and has a resistance for variable climatic and soil conditions. So far, there is no observable market on the use of biodiesel products. However, within a short period a significant number of foreign, local, and joint companies have invested in the biodiesel industry. Nevertheless, the search for feedstock other than jatropha is still at its ground level. The objective of this work was to synthesize and characterize biodiesel from Castor seed using homogeneous alkali catalyst $(\mathrm{KOH})$ via transesterification reaction and comparing the physico-chemical properties with international biodiesel standards.

\section{Materials and Methods}

\subsection{Chemicals and Apparatus}

Chemicals: Castor bean was purchased from local market and processed in to castor oil to be used as a raw material. The crude castor oils were neutralized to reduce the acid value using $\mathrm{NaOH}$ pellet and anhydrous Methanol of $99.9 \%$ purity; potassium hydroxide and other chemicals were of analytical reagent grade. Those chemicals, which were used during the experiments, were purchased from neway private limited company and used without further purification. Moreover, diesel oil was purchased from total diesel station from local market and used during the experimental studies.

Apparatus: The basic equipments used during the experimentations were oven dry, Glass reactor; temperature controlled hot plate equipped with magnetic stirrer, condenser, Centrifuge, hydrometer, Vibro viscometer, 
conical flask, different size beakers and flasks, sensitive balance, $\mathrm{PH}$ electrode, burette.

\subsection{Experimental Set Up and Descriptions}

\subsubsection{Raw material Preparation}

The de-pulped nuts were sun dried on the open floor for 10 days to remove the moisture from the seeds and to ease the detachment of the seeds from the nuts. Then a sample was randomly selected to determine moisture content in the nuts according to AOAC Standard (AOAC, 1980). $100 \mathrm{gm}$ of each sample was oven-dried at $100^{\circ} \mathrm{C}$ for $7 \mathrm{~h}$ in Debre Markos University, Agricultural College, plant and natural science Laboratory. The dry sample was cooled at room temperature in the desiccators and re-weighed to determine the weight loss. The test was replicated three times and the average moisture content of the castor bean was found to be $26 \%$. Then, the dry nuts were bagged in plastic and stored for subsequent use in a moisture free container.

\subsubsection{Cooking and Grinding}

Mortar and pestle were used to crush the beans into a paste (cake) in order to weaken or rupture the cell walls to release castor fat for extraction. The process of heating breaks down the cells containing the oil and liquefies the oil to improve the extraction process. Hence, the ratio of kernel weight to raw castor bean seed weight (W) was calculated by the following formula:

$$
\mathrm{W}=\frac{\text { mass of castor kernel }}{\text { mass of raw castor bean }} * 100
$$

\subsubsection{Oil Extraction}

The grounded fine powders of castor seed kernel was cooked and then dried for $8 \mathrm{~h}$ at $80^{\circ} \mathrm{C}$ in drying oven model 202-1AB. Cooking was done to coagulate protein (which is necessary to permit efficient extraction) and to free the oil for efficient pressing. The Castor bean oil was extracted from the seeds by soaking in hot boiled water until the oil floats and then allowed to settle until the impurities precipitated. The traditional procedures of castor oil extraction permit the extraction of oil from the kernel. However, it is very inefficient and time consuming. The percentage by mass of crude oil extracted from castor kernels was $19.2 \%$, which is about $34.9 \%$ of the oil present in the kernel [8]. The extracted oil was settled for two weeks then decanted and filtered with the help of filter paper to remove all the suspension particles from the extracted oil. After completing separation, the purified oil was stored in closed container at room temperature.

The amount of oil extracted was calculated with the following formula:

$$
\% \text { of castor oil }=\frac{\text { Mass of castor oil }}{\text { Initial mass of castor seed }} * 100
$$

\subsubsection{Pretreatment of Crude Castor Oil}

The extracted crude castor oil may contain phosphatides (phospholipids), gums and other complex compounds that could promote hydrolysis (increase FFA) of vegetable oil at the time of storage. In addition, during transesterification process, these compounds could interfere. Therefore, they were removed by acid pretreatment (degumming) process.

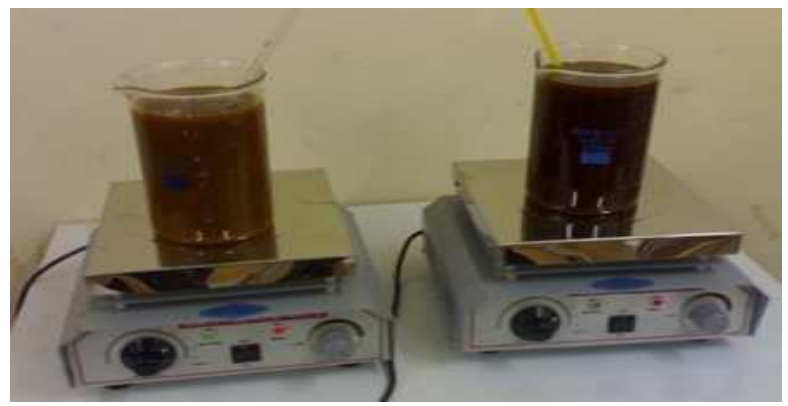

Figure 2.1. Experimental set up during degumming process for purification of crude castor oil

The acid pretreatment loss was calculated with the following formula:

$$
\text { Acid pretreatment loss }=\frac{\text { Weight of crude oil-Weight of pretreated oil }}{\text { Weight of crude oil }}
$$

To neutralizing the acid value and FFA of crude castor oil $0.5 \mathrm{~N} \mathrm{NaOH}$ was added to the degummed castor oil and heated the reaction mixture while stirring until the temperature reached $80^{\circ} \mathrm{C}$ to break any emulsion that might have formed during neutralization. Moreover, Sodium chloride ( $10 \%$ of the weight of oil) was also added to settle out the soap formed. Then the mixture was transferred into a separating funnel and allowed to stand for $1 \mathrm{hr}$ to remove the soap formed and hot water was added repeatedly to the oil until the soap remaining in the solution was removed. The caustic pretreated oil was then drawn off into a beaker. The final FFA content was determined and the caustic pretreatment loss was then calculated by the following formula:

$$
\text { Neutralization loss }=\frac{\text { weight of degmmued oil-weight of neutralized oil }}{\text { weight of degummed castor oil }}
$$

Finally, the neutralized oil was passed through hydration process by the addition of $30 \%$ hot distilled boiled water in which the mixture was stirred for 2 minutes and allowed to stand in the separating funnel until two clear phase observed. Thereafter, the aqueous layer was removed at the bottom. The procedure was repeated to ensure the removal of most gums and soaps. This process continued until the $\mathrm{pH}$ of the oil reached almost neutral. Then the oil was dried in oven at $120^{\circ} \mathrm{C}$ for $2 \mathrm{hrs}$ to remove the water present in it.

\subsubsection{Experimental Setup}

Batch transesterification reactor system was employed in this work as shown in Figure 2.2. A 500ml capacity three- 
necked glass reactor equipped with magnetic stirrer that provide the mixing requirement in a temperature controlled hot plate, which was a capable of controlling the temperature with a deviation of $1{ }^{\circ} \mathrm{C}$. In addition, the condenser provides cooling system for the experiment to control the leak of methanol by supplying cooled water in the inlet and the hot water was rejected in the outlet part.

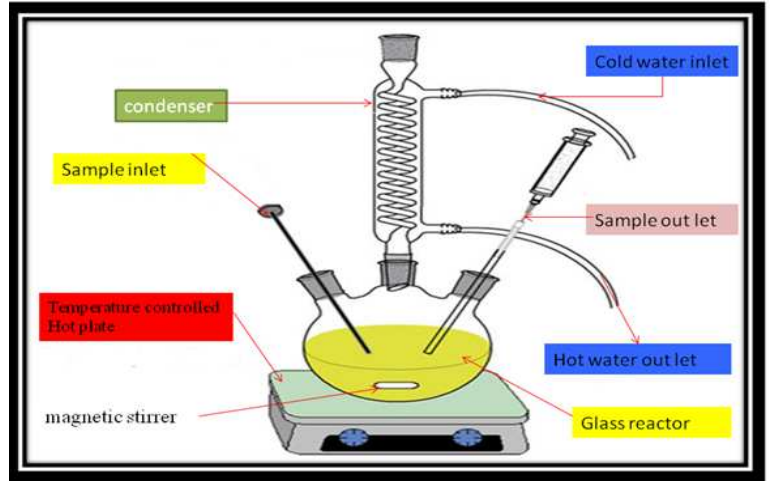

Figure 2.2. Experimental set-up for biodiesel production through transesterification $[15,16]$

\subsection{Characterization of Pretreated Castor Oil and its Biodiesel}

The physicochemical properties of pretreated oil have to be determined prior to biodiesel production process. The feedstock status determination helps not only to know the condition of the oil but also helps to make certain decision on whether it requires further treatment or not. The main physico-chemical properties that have to be determined are percentage of FFA content, AV, SN, IV, kinematic viscosity and density. These parameters directly or indirectly affect the quality of the final product the so-called biodiesel.

Moisture content determination of castor seed kernel: Empty dish was weighed with and without cooked, grounded, and dried castor kernel. Then 100gm of cleaned sample was weighed and dried in a digital drying oven model $202-1 \mathrm{AB}$ at $80^{\circ} \mathrm{C}$ for $8 \mathrm{hrs}$ and the weight was taken after every $2 \mathrm{hrs}$. After each $2 \mathrm{hrs}$, the sample was removed from the oven and placed in the desiccators for 30 minutes to cool. The procedure was repeated until a constant weight obtained. Finally, the weight was taken and compared with the initially recorded weight. The percentage weight in the kernel was calculated using the formula:

$$
\text { Moisture content }=\frac{W i-W f}{W f} * 100 \%
$$

Where, Wi = initial weight of sample before drying;

$\mathrm{Wf}=$ Weight of sample after drying.

Determination of Specific Gravity (SG): Density bottle (volumetric cylinder) was used to determine the density of the oil. A clean and dry bottle of $50 \mathrm{ml}$ capacity was weighed $\left(\mathrm{W}_{0}\right)$ and then filled with the oil, stopper inserted and reweighed to give $\left(\mathrm{W}_{1}\right)$. The oil was substituted with water after washing and drying the bottle and weighed to give $\left(\mathrm{W}_{2}\right)$. The expression for specific gravity is:

$$
\mathrm{SG}=\frac{\mathrm{w}_{1}-\mathrm{Wo}_{\mathrm{o}}}{\mathrm{w}_{2}-\mathrm{Wo}_{\mathrm{o}}}
$$

Similarly, the same procedure was applied to determine the SG of biodiesel using ASTMD 4052.

Determination of Viscosity $(\mu)$ : Digital Vibro viscometer was used to determine the viscosity of oil and biodiesel. The kinematic viscosity was determined at $40^{\circ} \mathrm{C}$ followed by ASTM D445-09. The temperature of a water bath was set at $40^{\circ} \mathrm{C}$ and calibrated. $50 \mathrm{ml}$ of sample was placed into the viscometer and allowed the viscometer and sample to equilibrate to the water bath for 30 minutes. The sample was kept in the water thermostat bath until it reaches the equilibrium temperature of $40{ }^{\circ} \mathrm{C}$. After maintaining the equilibrium temperature, the Vibro viscometer tip was inserted to the sample to measure the dynamic viscosity and the reading was taken from the controller

Determination of Acid Value (AV): The AV of the oil was determined using the method described by IUPAC (1979) and modified by Egan et al. (1981).

$25 \mathrm{ml}$ of diethyl ether and ethanol mixture was added to $5 \mathrm{gm}$ of oil in a $250 \mathrm{ml}$ conical flask and the solution was titrated with $0.1 \mathrm{~N}$ ethanolic $\mathrm{KOH}$ solution in the presence of 5 drops of phenolphthalein as indicator until the endpoint (colorless to pink) is recognized with consistent shaking. The volume of $0.1 \mathrm{~N}$ ethanolic $\mathrm{KOH}(\mathrm{V})$ for the sample titration was recorded.

The total acidity of oil in $\mathrm{mg} \mathrm{KOH} /$ gram was calculated using the following equation:

$$
\mathrm{AV}=\frac{56.1 * \mathrm{~N} * \mathrm{~V}}{\mathrm{~W}}
$$

Where, $\mathrm{V}=$ the volume expressed in milliliter of $0.1 \mathrm{~N}$ solution of ethanolic $\mathrm{KOH}$.

$\mathrm{W}=$ the weight of oil sample (the mass in gram of the test portion)

$\mathrm{N}=$ concentration of ethanolic $\mathrm{KOH}$

Then, the \% FFA value was calculated from the acid value using the following relationship:

$$
\% \mathrm{FFA}=\frac{\mathrm{AV}}{2}
$$

The acid value of biodiesel was determined by applying the ASTMD 664.

Determination of Saponification Number (SN): Indicator method was used as specified by ISO 3657 (1988). The SN determination was conducted by dissolving the oil in an ethanolic $\mathrm{KOH}$ solution. $2 \mathrm{~g}$ of the sample was weighed into a conical flask then $25 \mathrm{ml}$ of $0.1 \mathrm{~N}$ ethanolic potassium hydroxide solution was added. The content was constantly stirred, and allowed to boil gently for $60 \mathrm{~min}$. A reflux condenser was placed on the flask containing the mixture. Few drops of phenolphthalein indicator was added to the warm solution and then titrated with $0.5 \mathrm{M} \mathrm{HCl}$ (volume Va was recorded) to the endpoint until the pink color of the indicator just disappeared. Then a blank determination was 
carried out upon the same quantity of potassium hydroxide solution at the same time and under the same conditions and (volume $\mathrm{Vb}$ was recorded). The result was calculated using equation:

$$
\mathrm{SN}=\frac{56.1 * \mathrm{~N} *(\mathrm{Vb}-\mathrm{Va})}{\mathrm{W}}
$$

Where $\mathrm{W}=$ weight of oil taken in gram, $\mathrm{N}=$ normality of HCL solution,

$\mathrm{Va}=$ volume of HCL solution used in test in $\mathrm{ml}$,

$\mathrm{Vb}=$ volume of HCL solution used in blank in $\mathrm{ml}$.

The same procedure was used to determine the $\mathrm{SN}$ of biodiesel as discussed above.

Determination of Iodine Value (IV): The method specified by ISO 3961 (1989) was used. $0.4 \mathrm{~g}$ of the sample was weighed into a conical flask and $20 \mathrm{ml}$ of carbon tetra chloride was added to dissolve the oil. Then $25 \mathrm{ml}$ of Dam's (Iodine monochloride) reagent was added to the flask using a safety pipette in fume chamber. Stopper was then inserted and the content of the flask was vigorously swirled. The flask was then placed in the dark place for 2.5 hours. At the end of this period, $20 \mathrm{ml}$ of $10 \%$ aqueous potassium iodide and $125 \mathrm{ml}$ of water were added using a measuring cylinder. The content was titrated with $0.1 \mathrm{~N}$ sodium-thiosuphate solutions until the yellow color almost disappeared.

Few drops of $1 \%$ starch indicator was added and the titration continued by adding sodium thiosuphate drop wise until blue coloration disappeared after vigorous shaking. The same procedure was used for blank test and other samples. The iodine value (IV) is given by the expression:

$$
\mathrm{IV}=12.69 * \mathrm{~N} *\left(\frac{\mathrm{V} 2-\mathrm{V} 1}{\mathrm{M}}\right)
$$

Where, $\mathrm{N}=$ normality of sodium thiosuphate, $\mathrm{V} 1=$ Volume of sodium thiosuphate

V2 = Volume of sodium thiosuphate used for blank, $\mathrm{M}=$ Mass of the sample

The same procedure was used to determine the Iodine value of biodiesel.

Determination of Heating Value (Calorific Value): The HHV of the castor oil and its biodiesel was determined using the empirical formula suggested by Demirbas (1998).

$$
\mathrm{HHV}=49.43-[0.041(\mathrm{SN})+0.015(\mathrm{IV})]
$$

Determination of Cetane Number (CN), ASTMD 613: The Cetane number of the biodiesel was determined using the empirical formula suggested by (Kalayasiri et al., 1996), using the result of SN and IV of the biodiesel.

$$
\mathrm{CN}=46.3+\left(\frac{5458}{\mathrm{SN}}\right)-0.225(\mathrm{IV})
$$

Determination of Flash Point, ASTMD 93: The FP of the biodiesel was determined using empirical formula by Ayhan Demirbas (2008)[9]. The equation between FP and HHV for biodiesel is:

$$
\mathrm{HHV}=0.021 \mathrm{FP}+32.12
$$

\subsection{Experimental Design for Base Catalyzed Biodiesel Production}

In order to optimize the reaction factors, a five-level three-factor central composite design (CCD) was utilized in this study. In order to gain information regarding the interior of the experimental region and to evaluate the curvature, this study was conducted in 20 experiments in accordance with a $2^{3}$ complete factorial design, six central points and six axial points (star points). The distance of the star points from the center point is provided by $\alpha=\left(2^{\mathrm{n}}\right)^{1 / 4}$, in which $\mathrm{n}$ is the number of independent factors, for three factors $\alpha=1.68$ [10]. The variable ranges adopted, as provided in Table 2.1. Table 2.1 describes the coded and un coded independent factors. The methanol to oil molar ratio, catalyst concentration and reaction temperature were the independent variables selected to optimize the conditions for FAME production using $\mathrm{KOH}$ catalyst. The reaction period and rotational speed was set at optimum point where maximum conversion could be achieved based on literature data at atmospheric pressure for all runs. The responses measured were the yield of FAMEs. These independent variables were assigned as $(-1,1)$ interval where the low and high levels were -1 and +1 , respectively. The axial points was located at $( \pm \alpha, 0,0),(0, \pm \alpha, 0)$ and $(0,0, \pm \alpha)$ where $\alpha$ is the distance of the axial point from center and makes the design rotatable

Twenty experiments were carried out \& data was statistically analyzed by Design-Expert 8 program to find suitable model for the percentage of FAME as a function of the above three variables. The central values (zero level)

\begin{tabular}{|c|c|c|c|c|c|c|c|}
\hline \multirow{2}{*}{ Variable (Factors) } & \multirow{2}{*}{ Factor Coding } & \multirow{2}{*}{ Unit } & \multicolumn{5}{|c|}{ *Levels } \\
\hline & & & -1.68 & -1 & $\mathbf{0}$ & +1 & +1.68 \\
\hline Reaction temperature(T) & A & ${ }^{0} \mathrm{C}$ & 46.9 & 50 & 55 & 60 & 63.4 \\
\hline Methanol to Oil ratio(M) & B & - & 0.96 & 3 & 6 & 9 & 11.04 \\
\hline Amount of Catalyst(C) & $\mathrm{C}$ & $\mathrm{Wt} \%$ & 0.16 & 0.5 & 1 & 1.5 & 1.84 \\
\hline
\end{tabular}
chosen for experimental design were the Methanol to oil molar ratio of $6: 1$, Catalyst concentration of $1 \%(\mathrm{w} / \mathrm{w})$, and Temperature $55^{\circ} \mathrm{C}$.

Table 2.1. Independent variables and levels used in CCD for base-catalyzed transesterification process.

\subsection{Base-Catalyzed Transesterification Reaction}

Initially, pretreated Castor seed oil was poured into a three-necked $500 \mathrm{ml}$ glass reactor and then preheated at $120^{\circ} \mathrm{C}$ to remove the moisture content using temperature controlled hot plate for 30 minutes as shown in fig 2.2. In 
order to maintain the catalytic activity, the solution of $\mathrm{KOH}$ in methanol was freshly prepared so that prolonged contact with the air was not diminishing the effectiveness of the catalyst through interaction with moisture and carbon dioxide. The catalyst solution was added slowly to the preheated oil until the reaction was completed. After the reaction was accomplished, the mixture was allowed to settle under gravity for $24 \mathrm{hrs}$ in the separatory funnel at room temperature. During separation, two layers were formed in such a manner that the crude ester phase present at the top and the glycerol phase at the bottom. The upper layer consists of ME, methanol traces, residual catalyst and other impurities, whereas the lower layer consists of glycerin, excess methanol, catalyst and other impurities. The glycerin and other impurities were removed from biodiesel by opening the tap provided at the bottom.

\subsection{Purification of Biodiesel}

After separated from the glycerin layer, the MEs layer were purified by washing with warm distilled water by adding 1-2 drops of acetic acid at $60^{\circ} \mathrm{C}$ until the washing water have a neutral $\mathrm{pH}$ value. The gentle washing action of hot distilled water to crude ME ratios were 3:1. Gentle washing prevents the possibility of losing the ME due to the formation of emulsions and results in a rapid and complete phase separation [11]. Then, the excess methanol and any remaining water was removed from the $\mathrm{ME}$ layer by heating the product at $120{ }^{\circ} \mathrm{C}$ [7].

The primary purpose of biodiesel washing step was to remove any soap formed during transesterification reaction. In addition, warm water with acetic acid provides neutralization of the remaining catalyst and removes the formed salts. The use of warm water prevents precipitation of saturated fatty acid esters and retards the formation of emulsions with the use of gentle washing action. Finally, Biodiesel properties such as density, viscosity, FP, CN, AV, $\mathrm{SV}$, IV, and calorific value was determined and compared with ASTM6751 and EN14214 standards

\section{Results and Discussion}

\subsection{Castor Bean Oil Extraction and Purification Process}

Moisture Content Determination

The amount of sample was weighted using a sensitive balance for each experiment. Then, it was dried in digital drying oven of model $202-1 \mathrm{AB}$ at $80^{\circ} \mathrm{C}$ for 8 hours. Again, the weight of the sample after drying was measured. Five experiments was conducted and the moisture content was determined for each of them and the averaged value of castor kernel seed moisture content was found to be $3.82 \%$. This result varied for literature findings of $4.15 \%$ [12] and (5-7)\%[13].

\subsection{Pretreatment of Crude Castor Oil Processes}

Acid Pretreatment Process

Based on the method discussed in chapter 2: 3\% (v/v) of hot distilled water and $2 \%(\mathrm{v} / \mathrm{v})$ phosphoric acid is required for degumming crude Castor bean oil in order to remove phosphatides, gums and other complex compounds, which enhance the hydrolysis of FFA. Therefore, the crude oil was degumming using $40 \mathrm{ml}$ of phosphoric acid and $60 \mathrm{ml}$ of distilled hot water. After treatment, the amount of oil loss was determined and obtained as $4 \%(80 \mathrm{ml})$. This shows that crude castor oil contains water insoluble impurities which increases FFA and phosphoric acid have a power to remove these impurities.

Caustic Pretreatment Process

Norris (1982) points out that during the caustic pretreatment of the high FFA oils, a loss of oil is normally three times the amount of FFA. This has been observed in soybean and cottonseed oil with high FFA of more than $5 \%$. In this study, the caustic pretreatment reduces the FFA of crude castor oil from 3.52 to $0.932 \%$. From 1.92 liter $(1.84 \mathrm{~kg})$ of acid pretreated castor oil, $14 \%$ oil was loosed during caustic pretreatment . This is higher than that of acid pretreatment oil losses due to saponification and occlusion of oil in the soap stock. Moreover, the amount of $\mathrm{AV}$ present in crude castor oil before treatment was $7.04 \mathrm{mgKOH} / \mathrm{g}$ whereas after neutralization using caustic soda, the acid value minimize to $1.86 \mathrm{mgKOH} / \mathrm{g}$ that shows caustic soda have a power to neutralize the FFA found in the oil.

\subsubsection{Characterization of Pretreated Castor Bean Oil}

Using the various formulae as indicated in the experimental procedure, the physico-chemical properties of the pretreated oil were evaluated. The density, viscosity, AV, percentage of FFA, SN, IV and HHV of the purified Castor bean oil were determined and the results are presented in Table 3.1

Table 3.1. Physico-chemical properties of crude and pretreated castor oil

\begin{tabular}{lccc}
\hline \multirow{2}{*}{ Property } & \multicolumn{2}{c}{ Experimental Result } & Unit \\
& Crude Castor oil & Pretreated castor oil & - \\
\hline Specific Gravity & 0.9628 & 0.9618 & $\mathrm{~g} / \mathrm{ml}$ \\
Density at $15^{\circ} \mathrm{C}$ & 0.9628 & 0.9618 & $\mathrm{~mm} / \mathrm{s}$ \\
Kinematic viscosity at $40^{\circ} \mathrm{C}$ & - & 208.96 & $\mathrm{mg} \mathrm{KOH} / \mathrm{g}$ oil \\
Acid Value & 7.049 & 1.862 & $\%$ \\
Composition of Free Fatty Acid & 3.52 & 0.931 & $\mathrm{mg} \mathrm{KOH} / \mathrm{g}$ oil \\
Saponification Number & - & 185.3645 & $\mathrm{MJ} / \mathrm{kg}$ \\
Higher Heating Value & - & 39.7 & $\mathrm{gL} / 100 \mathrm{~g}$ \\
Iodine value & - & 87.9 & \\
\hline
\end{tabular}


Specific gravity: The Specific gravity values for both crude and refined oil were obtained nearly the same (0.9618). Hence, the density of the oil is determined using the specific gravity. Therefore, the density of oil was $0.9618 \mathrm{~g} / \mathrm{ml}$ that are in agreement with the reported in literature [14].

Kinematic viscosity: The viscosity of oil was measured using Vibro viscometer. The device detects the dynamic viscosity, which is the resistance to flow with vibration. The observed kinematic viscosity was $208.96 \mathrm{~mm}^{2} / \mathrm{sec}$ that is in agreement with literature data [13].

Acid Value: The chemical properties analysis shown in Table 3.1 indicates that the acid value of crude and pretreated castor oil is $7.04 \mathrm{mgKOH}$ and $1.862 \mathrm{mg} \mathrm{KOH} / \mathrm{g}$ of oil respectively. The value is higher in crude oil due to FFA (3.52\%) present; while it is less for degummed and neutralized oil because of $0.5 \mathrm{~N}$ of $\mathrm{NaOH}$ used in the treatment of the crude oil, which must have neutralized some of the free fatty acid present in it. The result agrees within the range specified in literature.

The FFA value was also calculated from the AV relation using Eq (2.5a) and determined as $3.52 \%$ and $0.931 \%$ for crude and purified oil respectively. Therefore, the percentage of FFA value in purified oil was in range to use alkali-catalyzed transesterification process.

Saponification Value/Number (SN): The $\mathrm{SN}$ was calculated using Equation (2.6) and the observed value was taken for three trials and the average value obtained as $185.3645 \mathrm{mg}$ of $\mathrm{KOH} / \mathrm{g}$ of oil, which is in agreement with the result specified for quality castor oil.

Higher Heating Value: It was determined using empirical formula given in Equation (2.10). The calculated value of $\mathrm{HHV}$ in the oil was equal to $39.7 \mathrm{MJ} / \mathrm{Kg}$

Iodine Value: It is the measure of the degree of unsaturation of a particular oil or fat. It was determined using titration. The observed value of iodine in the oil was equal to $87.9 \mathrm{~g} \mathrm{I} / 100 \mathrm{~g}$ which is in the range $(82-88 \mathrm{I} 2 / 100 \mathrm{~g})$ reported in literature[15].

\subsection{Transesterification Reaction}

The yield and characteristics of biodiesel is depending on the type of oil used due to variation in the fatty acid composition and other characteristics of oil. Taking into consideration this aspect, the castor oils from inedible sources have been taken as a raw material for the preparation of biodiesel using $\mathrm{KOH}$ catalyst and methanol alcohol.

Various reaction parameters such as alcohol to oil molar ratio, concentration of catalyst and temperature have been taken for the study to analyze their effect on the yield and the characteristics of biodiesel. The results obtained are discussed as follows:

\subsubsection{Effect of Operating Conditions on Biodiesel Yield Effect of Methanol to Oil Molar Ratio}

After selecting methanol for transesterification reaction, the effect of its concentration on yield and characteristics of biodiesel from castor oils pretreated with phosphoric acid and caustic soda was investigated. Biodiesel was prepared from this oil at different molar ratio of methanol to oil. As shown in Figure 3.1, the methanol to oil molar ratio is one of the most factors that affect the conversion of triglyceride to FAME. The Stoichiometry of the transesterification reaction requires three mol of alcohol per one mol of triglyceride to yield three mol of fatty esters and one moles of glycerol [6]. However, to shift the transesterification reaction to the right and to achieve equilibrium, it is necessary to either use more than $100 \%$ excess alcohols or remove one of the products from the reaction mixture continuously in order to produce more FAME products.

Several researchers studied the effect of molar ratio (from 1:1 to 6:1) on ester conversion with vegetable oils( Soybean, sunflower, peanut and cottonseed) behaved similarly and achieved highest conversions (93-98\%) at a 6:1 molar ratio[7] where as experiment conducted by Dennis Y.C leung(2008) has recorded a yield of $93.1 \%$ for a methanol-to-oil ratio of $8: 1$ and 10:1.

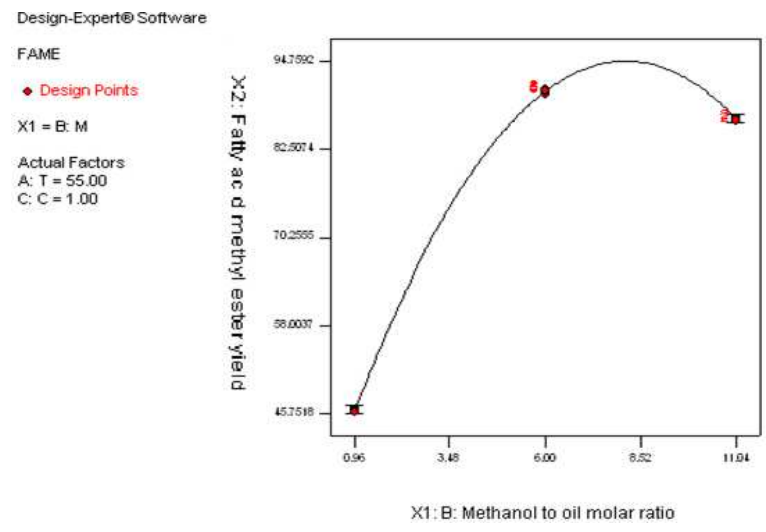

Figure 3.1. The effect of methanol to oil ratio verses methyl ester yield

Similarly, the result obtained in this study as shown in Figure 3.1, the methanol-to-oil ratio has a great influence to the yield of methyl ester. When the methanol to oil molar ration increased from $0.96: 1$ to $8.10: 1$, the methyl ester yield is increased and the saponification value decreases. However, the yield started to decrease when the molar ratio increase beyond $1: 8.10$. This is due to separation problem resulted from excessive methanol, minimize the contact of access of triglyceride molecules on the catalyst's active sites, which could decrease the catalyst activity, losses during washing step and interference the separation of glycerol because of increasing glycerol solubility. Moreover, methanol with one polar hydroxyl group can work as an emulsifier that enhances emulsion causing separation of ester layer difficult from the water layer (Leung and Guo, 2006) and when glycerin remains in solution, it will drive the equilibrium back to the left, which lowering the yield of esters. Therefore, the optimum operating condition for biodiesel production using $\mathrm{KOH}$ catalyst is obtained at $8.10: 1$ methanol to oil molar ratio in this study.

The Effect of catalyst concentration: To study the effect 
of catalyst concentration on yield and characteristics of biodiesel obtained from castor oil, the biodiesel was prepared with different amount of catalyst ( 0.16 to $1.84 \%$ by weight of oil). The trend of yield with respect to catalyst concentration is shown in Figure 3.2. As we could understand from the figure below, the yield of biodiesel increases with increase in amount of catalyst up to $1.22 \%$ and then decreases. At lower concentration of catalyst, the reaction is incomplete as a result lower yield was obtained where as at higher concentration of catalyst ,the yield decreases due to the enhancement of saponification reaction causing triglyceride to form soap faster than ester. Dorado et al. (2004) and Encinar et al. (2005) have reported that the formation of soap in presence of high amount of catalyst increases the viscosity of the reactants and thus lowers the rate of biodiesel production

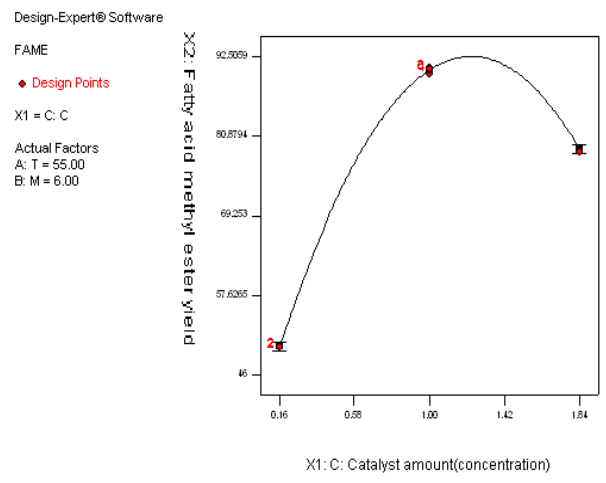

Figure 3.2. The effect of catalyst amount verses methyl ester yield

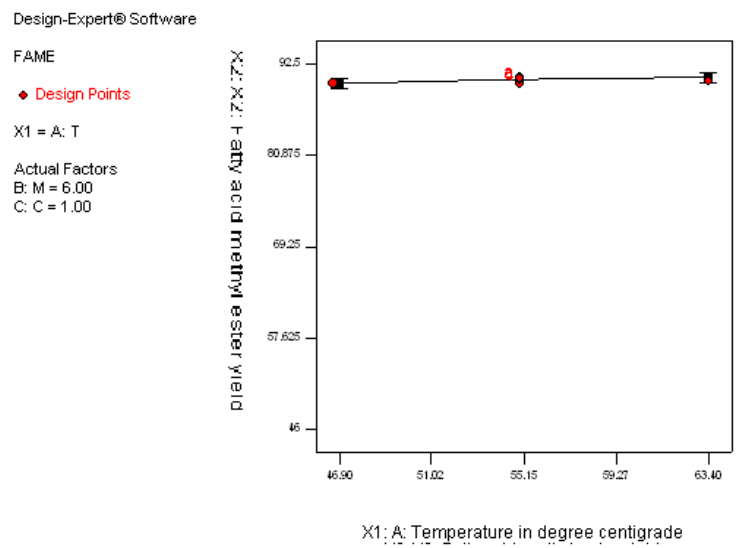

Figure 3.3. The effect of reaction temperature verses methyl ester yield.

Effect of reaction temperature: Several researchers have studied the effect of temperature on conversion of oils and fats into biodiesel. Their results indicate that as the temperature increase, the methyl ester content increase due to the viscosity of the oil decreases, which resulted in an increase in the solubility of the oil in the methanol, leading to an improvement in the contact between oil and methanol. However, in this experiment, the temperature increment effect was not significant on biodiesel yield but there is a little change on biodiesel yield as the temperature increases and decreases as show in Figure 3.3. The increase in the yield of FAME at higher reaction temperature is due to higher rate of reaction and molecular collision. Moreover, from the experimental model analysis and ANOVA, the pvalue of the temperature term in both liner and quadratic model was greater than the $\mathrm{p}$-value limit. Hence, the result showed that increases in reaction temperature did not significantly affect the fatty acid ester content at any of the tested oil-to-methanol molar ratios in the process of castor oil transesterification. In a similar case, researchers reported that the reaction temperature did not affect the castor oil alcoholysis reaction because castor oil is soluble in ethanol at room temperature [17]. However, other studies show that the reaction temperature exerted a significant degree of influence on the rate of biodiesel synthesis using vegetable oils and fats as feedstock [10].

\subsection{Optimization of Biodiesel Production from Castor Oil in Base-Catalyzed Transesterification Process Using Response Surface Method}

The selected independent reaction parameters (reaction temperature, methanol to oil molar ratio and weight of catalyst) were optimized using design expert software. In contrast with the classical optimization process, this may lack to account the effectiveness of different combination of parameters. Response surface method (RSM) provides elaborate vision over various combinations of parameters.

In order to optimize the reaction factors for castor oil biodiesel production, a CCD with a five-level three-factor design was employed. Table 3.2 describes these experimental parameters and their results based on the CCD experimental design. Twenty designed experiments were conducted and analyzed with multiple regressions using Design-Expert 8.0.7.1 software. Regression analysis yield three linear coefficients $(\mathrm{A}, \mathrm{B}, \mathrm{C})$, three quadratic coefficients $\left(\mathrm{A}^{2}, \mathrm{~B}^{2}, \mathrm{C}^{2}\right)$ and three cross product coefficients (AB, AC, BC) for the full model (Table 3.3). Table 3.3 also describes the ANOVA for the response surface quadratic model. The transesterification was carried out using the previously shown experimental setup at Figure2.1. The reaction was carried out using a $500 \mathrm{ml}$ capacity three necked glass reactor, which is equipped with a magnetic stirrer in a temperature-controlled hot plate. The statistical analysis of the biodiesel was discussed below.

Statistical analysis on Factors Affecting Biodiesel Yield

The Design Expert 8.0.7.1 program was used in the regression analysis and analysis of variance (ANOVA). The Statistical software program was used to generate surface and counter plots using the fitted equation obtained from the regression analysis, holding one of the independent variables constant. Experimental as well as predicted values of percentage conversion of the oil to biodiesel at the design points are shown in Table 3.2. The actual yields of biodiesel produced at different process parameters were calculated and obtained ranged from $46 \%$ to $92.5 \%$. The yield of the transesterification processes were calculated as the sum of weight of FAME produced to weight of oil used multiplied by 100 . The formula is given as: 
Yield of FAME $=\frac{\text { weight of FAME }}{\text { weight of oil used }} * 100 \%$

Table 3.2. CCD arrangement and response for alkali transesterification reaction processes

\begin{tabular}{|c|c|c|c|c|c|c|c|c|c|c|}
\hline \multirow{2}{*}{ Std } & \multirow{2}{*}{ Run } & \multicolumn{3}{|c|}{ Coded factor } & \multicolumn{3}{|c|}{ Actual factors } & \multicolumn{3}{|c|}{ FAME (\%) } \\
\hline & & $\mathbf{A}$ & B & $\mathbf{C}$ & T: Temperture & M: Methanol & C: Catalys & Actual value & Predicted value & Residual \\
\hline 6 & 1 & +1 & -1 & +1 & 60.0 & 3.00 & 1.50 & 72 & 71.36 & 0.64 \\
\hline 15 & 2 & 0 & 0 & 0 & 55.00 & 6.00 & 1.00 & 90.5 & 90.50 & $-1.194 \mathrm{E}-003$ \\
\hline 5 & 3 & -1 & -1 & +1 & 50.00 & 3.00 & 1.50 & 70 & 70.12 & -0.12 \\
\hline 9 & 4 & -1.68 & 0 & 0 & 46.59 & 6.00 & 1.00 & 90 & 89.96 & 0.040 \\
\hline 12 & 5 & 0 & +1.68 & 0 & 55.00 & 11.05 & 1.00 & 86.5 & 86.73 & -0.23 \\
\hline 13 & 6 & 0 & 0 & -1.68 & 55.00 & 6.00 & 0.16 & 50 & 50.15 & -0.15 \\
\hline 11 & 7 & 0 & -1.68 & 0 & 55.00 & 0.95 & 1.00 & 46 & 46.31 & -0.31 \\
\hline 14 & 8 & 0 & 0 & +1.68 & 55.00 & 6.00 & 1.84 & 78.6 & 78.99 & -0.39 \\
\hline 16 & 9 & 0 & 0 & 0 & 55.00 & 6.00 & 1.00 & 90 & 90.50 & -0.50 \\
\hline 17 & 10 & 0 & 0 & 0 & 55.00 & 6.00 & 1.00 & 90.6 & 90.50 & 0.099 \\
\hline 8 & 11 & +1 & +1 & +1 & 60.00 & 9.00 & 1.50 & 92.5 & 92.39 & 0.11 \\
\hline 18 & 12 & 0 & 0 & 0 & 55.00 & 6.00 & 1.00 & 90.5 & 90.50 & 0.099 \\
\hline 1 & 13 & -1 & -1 & -1.68 & 50.00 & 3.00 & 0.50 & 51 & 50.72 & 0.28 \\
\hline 4 & 14 & +1 & +1 & -1 & 60.00 & 9.00 & 0.50 & 78 & 77.50 & 0.50 \\
\hline 2 & 15 & +1 & -1 & -1 & 60.00 & 3.00 & 0.50 & 51 & 50.96 & 0.038 \\
\hline 19 & 16 & 0 & 0 & 0 & 55.00 & 6.00 & 1.00 & 90.8 & 90.50 & 0.30 \\
\hline 7 & 17 & -1 & +1 & +1 & 50.00 & 9.00 & 1.50 & 92 & 91.66 & 0.34 \\
\hline 10 & 18 & +1.68 & 0 & 0 & 63.41 & 6.00 & 1.00 & 90.2 & 90.78 & -0.58 \\
\hline 3 & 19 & -1 & +1 & -1 & 50.00 & 9.00 & 0.50 & 77.5 & 77.76 & -0.26 \\
\hline 20 & 20 & 0 & 0 & 0 & 55.00 & 6.00 & 1.00 & 90.7 & 90.50 & 0.20 \\
\hline
\end{tabular}

Development of Regression Model Equation

The model equation that correlates the response (yield of the castor oil to FAME) of the transesterification process variables in terms of actual value after excluding the insignificant terms was given below. The predicted model for percentage of FAME content (FAME \%) in terms of the coded factors is shown below.

Final Equation in Terms of Coded Factors:

$$
\text { FAME }=+90.50+0.24 * \mathrm{~A}+12.02 * \mathrm{~B}+8.57 * \mathrm{C}-0.12 * \mathrm{~A} * \mathrm{~B}+0.25 * \mathrm{~A} * \mathrm{C}-1.37 * \mathrm{~B} * \mathrm{C}-0.046 * \mathrm{~A}^{2}-8.48 * \mathrm{~B}^{2}-9.17 * \mathrm{C}^{2}
$$

Where, $\mathrm{A}=$ Reaction temperature, $\mathrm{B}=$ Molar ratio of methanol to oil, $\mathrm{C}=$ weight of catalyst

The statistical analysis of the ANOVA is given in .Table 3.3. The multiple regression coefficients were obtained by employing a least square technique to predict quadratic polynomial model for the FAME content (Table 3.4). Hence, the best fitting model was determined. The model was selected based on the highest order polynomial where the additional terms were significant and the model was not aliased as suggested by the software. The coefficients of the response surface model as provided by the above quadratic model equation was also evaluated. From the ANOVA of response surface quadratic model for FAME conversion, the Model F-value of 2808.95 and Prob $>$ F of $<0.0001$ implied that the model was significant. For the model terms, values of Prob $>\mathrm{F}$ less than 0.0500 indicate that the model terms are significant. In this case $\mathrm{B}, \mathrm{C}, \mathrm{BC}, \mathrm{B}^{2}$ and $\mathrm{C}^{2}$ are significant model terms (all have Prob $>$ F less than 0.050). 
This tells us the methanol to oil ratio, catalyst, and their quadratic terms affect the yield much significantly. However, the interaction terms were found to be insignificant except $\mathrm{BC}$ Since the values greater than 0.1000 indicates the model terms were insignificant (Table 3.3).

As we observe from p-values of the model coefficients in Table 3.3, the value of the methanol to oil molar ratio and catalyst in both linear and quadratic model are much less than 0.0001. This indicated that they are the most significant in determining the model than the rest. However, in order to minimize error, all of the coefficients were considered in the design. The lack of fit from the ANOVA analysis indicated that the model does indeed represent the actual relationships of reaction parameters, which are well within the selected ranges. The Lack of Fit F-value of 4.17 implies its insignificant relative to the pure error. Nonsignificant lack of fit is good because we want the model to fit.

Table 3.3. Analysis of variance (ANOVA) for response surface quadratic model of alkali transesterification process

\begin{tabular}{|c|c|c|c|c|c|c|}
\hline Source & Sum of Squares & Difference & Mean Square & F -Value & P-value, Prob $>$ F & Significance \\
\hline Model & 5072.81 & 9 & 563.65 & 2808.95 & $<0.0001$ & Significant \\
\hline A & 0.82 & 1 & 0.82 & 4.06 & 0.0715 & Not Significant \\
\hline B & 1972.12 & 1 & 1972.12 & 9828.14 & $<0.0001$ & Significant \\
\hline $\mathrm{C}$ & 1004.06 & 1 & 1004.06 & 5003.75 & $<0.0001$ & Significant \\
\hline $\mathrm{AB}$ & 0.13 & 1 & 0.13 & 0.62 & 0.4483 & Not Significant \\
\hline $\mathrm{AC}$ & 0.50 & 1 & 0.50 & 2.49 & 0.1455 & Not Significant \\
\hline $\mathrm{BC}$ & 15.13 & 1 & 15.13 & 75.38 & $<0.0001$ & Significant \\
\hline$A^{2}$ & 0.031 & 1 & 0.031 & 0.15 & 0.7037 & Not Significant \\
\hline $\mathrm{B}^{2}$ & 1035.94 & 1 & 1035.94 & 5162.65 & $<0.0001$ & Significant \\
\hline $\mathrm{C}^{2}$ & 1211.27 & 1 & 1211.27 & 6036.40 & $<0.0001$ & Significant \\
\hline Residual & 2.01 & 10 & 0.20 & - & - & - \\
\hline Lack of Fit & 1.62 & 5 & 0.32 & 4.17 & 0.0717 & Not Significant \\
\hline Pure Error & 0.39 & 5 & 0.078 & - & & \\
\hline Cor Total & 5074.81 & 19 & & & & \\
\hline
\end{tabular}

Table 3.4. Regression coefficients and significance of response surface quadratic model for the base catalyzed

\begin{tabular}{|c|c|c|c|c|c|c|}
\hline Factor & Coefficient estimate & Difference & Standard error & 95\%CI low & 95\% CI high & VIF \\
\hline Intercept & 90.50 & 1 & 0.18 & 90.09 & 90.91 & \\
\hline A-T & 0.24 & 1 & 0.12 & -0.026 & 0.51 & 1.00 \\
\hline B-M & 12.02 & 1 & 0.12 & 11.75 & 12.29 & 1.00 \\
\hline $\mathrm{C}-\mathrm{C}$ & 8.57 & 1 & 0.12 & 8.30 & 8.84 & 1.00 \\
\hline $\mathrm{AB}$ & -0.12 & 1 & 0.16 & -0.48 & 0.23 & 1.00 \\
\hline $\mathrm{AC}$ & 0.25 & 1 & 0.16 & -0.10 & 0.60 & 1.00 \\
\hline $\mathrm{BC}$ & -1.37 & 1 & 0.16 & -1.73 & -1.02 & 1.00 \\
\hline $\mathrm{A}^{2}$ & -0.046 & 1 & 0.12 & -0.31 & 0.22 & 1.02 \\
\hline $\mathrm{B}^{2}$ & -8.48 & 1 & 0.12 & -8.74 & -8.22 & 1.02 \\
\hline $\mathrm{C}^{2}$ & 9.17 & 1 & 0.12 & -9.43 & -8.90 & 1.02 \\
\hline
\end{tabular}

Final Equation in Terms of Actual Factors:

FAME $=32.29297+0.20210 * \mathrm{~T}+16.68521 * \mathrm{M}+90.49174 * \mathrm{C}-8.33333 \mathrm{E}-003 * \mathrm{~T} * \mathrm{M}+0.10000 * \mathrm{~T} * \mathrm{C}-0.91667 * \mathrm{M} *$ $\mathrm{C}-1.84764 \mathrm{E}-003 * \mathrm{~T}^{2}-0.94205 * \mathrm{M}^{2}-36.67147 * \mathrm{C}^{2}$

Table 3.5. Model adequacy of quadratic model for alkali catalyzed transesterification

\begin{tabular}{cccccc}
\hline Std. Dev & Mean & C.V. \% & R-Squared & AdjR-Squared & Pred R Squared \\
\hline 0.45 & 78.42 & 0.57 & 0.9996 & 0.9992 & 0.9973 \\
\hline
\end{tabular}

Where, $\mathrm{T}=$ reaction temperature, $\mathrm{M}=$ molar ratio of methanol to oil, $\mathrm{C}=$ weight of catalyst
Model Adequacy Check

The quality of the model developed was evaluated based 
on the correlation coefficient value, $R$ square $\left(R^{2}\right)$. The $R^{2}$ value for Equation (3.1) was 0.9996. This indicated that $99.96 \%$ of the total variation in the biodiesel yield was attributed to the experimental variables studied. The closer the $\mathrm{R}^{2}$ value to unity, the better the model will be, as it will give predicted values, which are closer to the actual values for the response

The Pred R-Squared" of 0.9973 is in reasonable agreement with the "Adj R-Squared" of 0.9992. "Adeq Precision" measures the signal to noise ratio. A ratio greater than 4 is desirable. The model ratio of 145.489 indicates an adequate signal. This model can be used to navigate the design space. The value of the adjusted coefficient of determination (Adj $\mathrm{R}^{2}=0.9992$ ) is also high, thus indicating the significance of the model as well as the value of coefficient of variation $(\mathrm{CV})$ is low $(0.57 \%)$, thereby indicating the reliability of the results of the fitted model.

From the ANOVA and regression analysis on Table 3.3 and Table3.4 respectively, it can be seen that the linear terms $(\mathrm{B}, \mathrm{C})$, the quadratic term $\left(\mathrm{B}^{2}, \mathrm{C}^{2}\right)$ and the cross product $\mathrm{BC}$ were significant (because Prob $>\mathrm{F}$ less than 0.05 ), but the interactions (cross products) $\mathrm{AB}, \mathrm{AC}$ and $\mathrm{A}$, $\mathrm{A}^{2}$ were insignificant.

The graph of the predicted values obtained using the developed correlation versus actual values forms a line of unit slope, i.e. the line of perfect fit with points corresponding to zero error between predicted values and
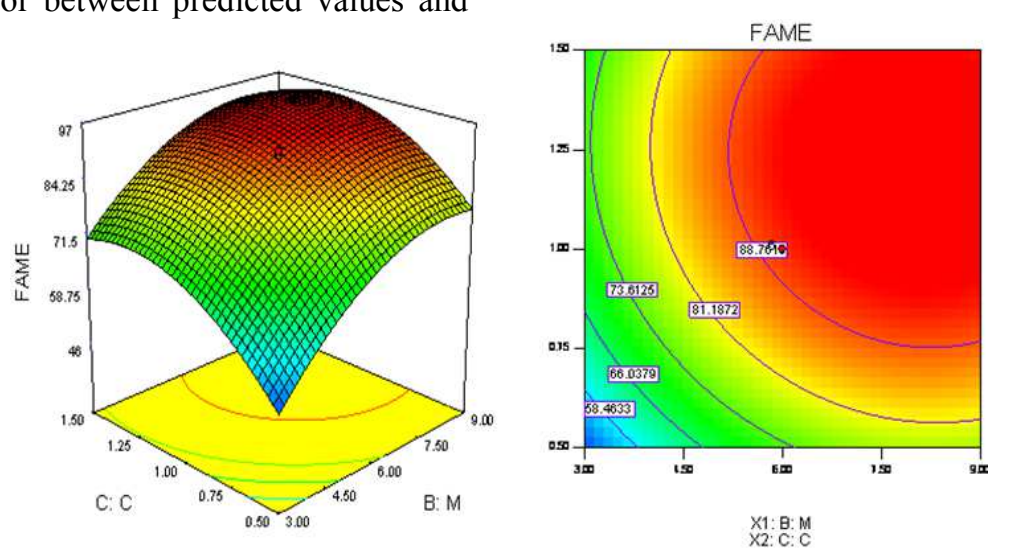

(a) Methanol to oil ratio verses catalyst amount when reaction temperature @ $55^{\circ} \mathrm{C}$
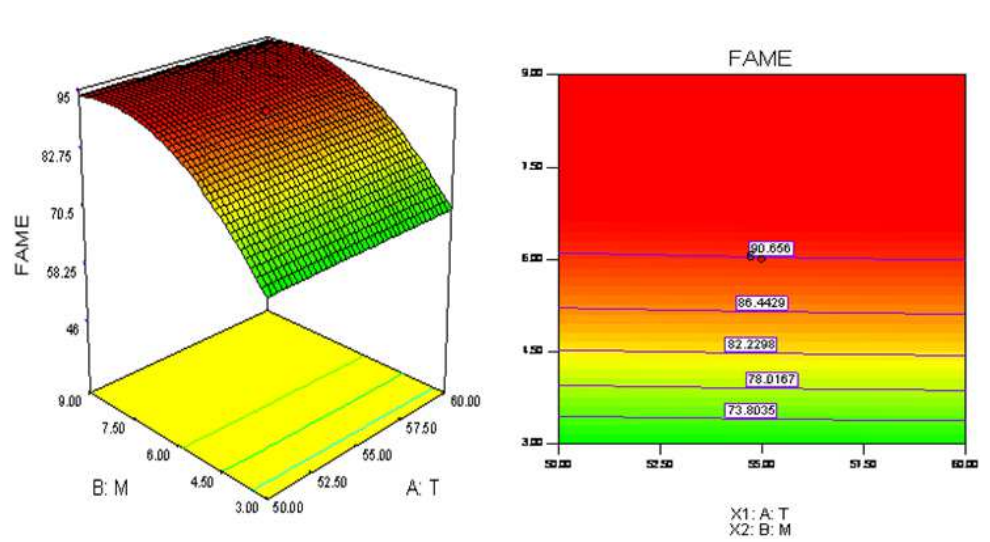

(b)Methanol to oil ratio verses Reaction temperature when the catalyst weight is $1 \%$ yield

actual values as shown in Figure 3.4. The results in Figure 3.4 demonstrated that the regression model equation provided a very accurate description of the experimental data, in which all the points are very close to the line of perfect fit. This result indicates that it was successful in capturing the correlation between the threetransesterification process variables to the yield of FFA.

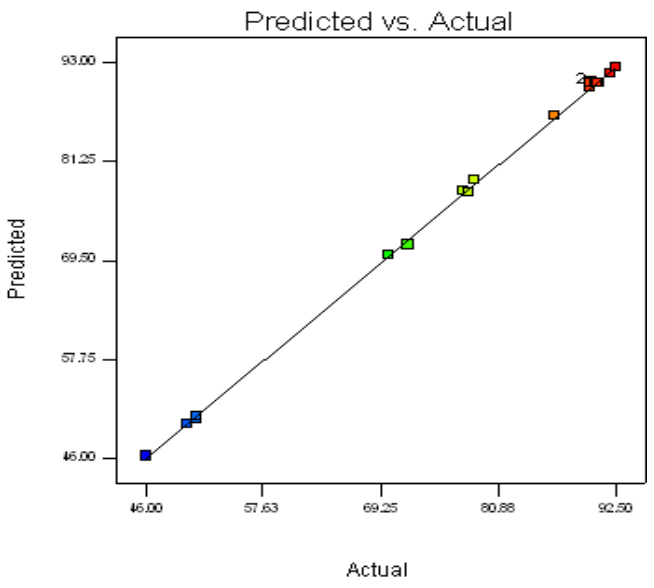

Figure 3.4. Plot for actual vs. predicted value of FAME yield

Effect of interactive operating conditions on biodiesel 

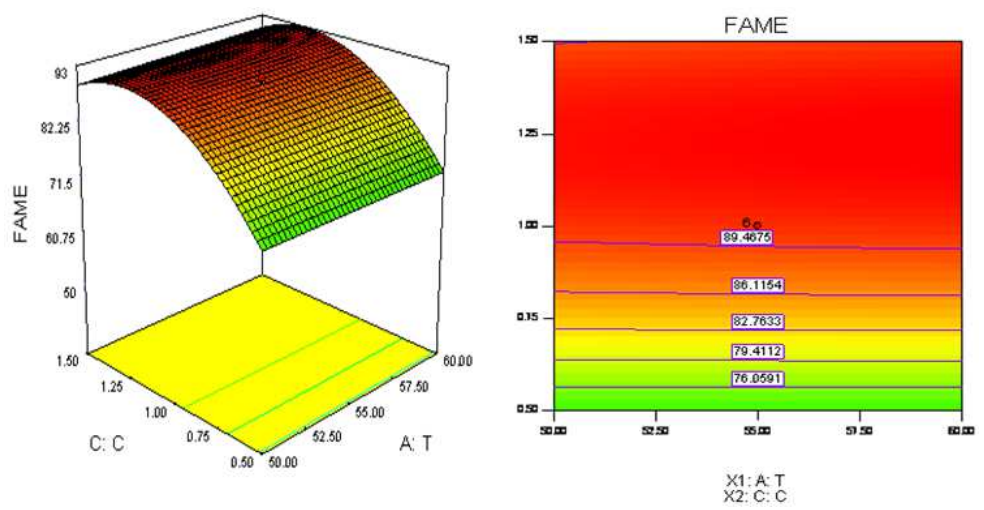

(c). Catalyst amount verses reaction temperature when the molar ratio is $6: 1$.

Figure 3.5. Response surface (to the left) \& Contour (to the right) plot of FAME yield (\%) in terms of coded factors (a, $b$ \& $c$ )

Surface and Contour plots (Figure 3.5a-c) were drawn to show the relationships between dependent and independent variables of the developed model. Each contour curve presented the effect of two variables on the methyl ester yield, holding the third variable at constant level. The third variable is held at the selected zero level. However, the interaction factor also must be considered since the individual effect plot does not give information regarding the significant interaction involved. Remarkable interaction between the independent variables could be observed, if the contour plots had an elliptical profile. The relationship between independent and dependent variables of the developed model in the response surface plots at the stationary value of $6: 1$ methanol-to-oil molar ratio, $1 \%$ of catalyst concentration and $55^{\circ} \mathrm{C}$ Reaction temperature is shown in Figure 3.5.

From Equation (3.1), it was clearly shown that, all the linear terms had positive coefficients, whereas the quadratic terms and the interaction terms had negative coefficients except AC. Therefore, an increase in temperature, $\mathrm{KOH}$ and methanol to oil molar ratio to a certain extent could result in a higher percentage of FAME. However, a reduction in the percentage of FAME could be obtained when using too high $\mathrm{KOH}$, and methanol to oil molar ratio. Figure $3.5 \mathrm{a}$ showed that, strong interaction between methanol to oil molar ratio (M) and $\mathrm{KOH}$ catalyst concentration (C). This can also be confirmed by the high p-values of the interaction parameters. It could also be seen from Figure $3.5 \mathrm{a}$, the FAME yield increased with increasing catalyst concentration at first. However, when the catalyst concentration reached $1.22 \%$ by weight of batch oil, the reverse trend was observed. Similar pattern was followed when increasing methanol to oil molar ratio. This is due the positive coefficient for the linear parameters (A B, and C) played the main role when the $\mathrm{KOH}$ catalyst concentration and methanol/oil molar ratio were at lower level. While at higher level, the interaction as well as the quadratic terms shows negative significant effect that leads to decrease the yield since the methanol and triglyceride in the oil are immiscible. Addition of catalyst can facilitate the transesterification reaction and rapidly increase the yield.
However, when the catalyst concentration was too high, soap could be quickly formed which made the separation of glycerol from biodiesel more difficult, thus reducing the yield. Similarly, the increase of the methanol amount, on one side, it will drive the reaction to the right since the reaction is an equilibrium process; on the other hand, excess methanol will help to increase the solubility of glycerol, which favors the backward reaction to the left. Therefore, the yield of FAME is decreasing.

Figure $3.5 \mathrm{~b}$ showed that, the effect of methanol to oil ratio and the reaction temperature when the level of catalyst concentration was fixed. At low methanol to oil ratio, the percentage of FAME increased with reaction temperature increase. In addition, the FAME yield increases with increased molar ratio at a certain level.

Figure $3.5 \mathrm{c}$ showed that, the effect of reaction temperature and catalyst concentration on the methyl ester yield when the level of methanol/oil molar ratio was fixed. At a certain level of catalyst concentration, increase in reaction temperature $(\mathrm{T})$, increases the methyl ester yield. An explanation to this has been attributed to the fact that, higher initial temperature helps in faster settlement of glycerol. However, the increments of temperature affect the FAME yield in a positive manner until $60^{\circ} \mathrm{C}$. After that, the effect was negligible. This could be explained by the higher p-value and the negative coefficient for the reactive and quadratic term in the model, which indicates nonsignificant effect.

\section{Optimization of Process Variables}

The results above have shown that threetransesterification process variables and the interaction among the variables that affect the yield of FAME. Therefore, the next step is to optimize the process variables in order to obtain the highest yield using the model regression developed. The methanol to oil molar ration, catalyst weight and the interaction between them are highly and significantly affect the transesterification process. From optimization function in Design Expert 8.0.7.1, it was predicted that at the following conditions (8.10:1 methanol to oil molar ratio, $1.22 \%$ catalyst concentration and 59.89 ${ }^{0} \mathrm{C}$ of reaction temperature) an optimum FAME yield of 
$94.5 \%$ could be obtained. In order to verify this prediction, experiments were conducted and the results were comparable with the prediction. It was found that the experimental value of $93.5 \%$ of FAME content, which agreed well with the predicted value. Therefore, this study shows that $\mathrm{KOH}$ is a potential catalyst for the production of biodiesel from castor bean oil via homogeneous transesterification process.

The optimization result also tells the same result as the ANOVA output. The ANOVA output shows that the methanol to oil molar ratio, catalyst weight and the interaction between them are highly and significantly affect the transesterification process.

\subsection{Physicochemical Properties of Biodiesel}

Specific gravity: It was found and observed in the range of 0.920 to 0.932 . Therefore, the density of the biodiesel was measured and values were found to be in the range of 920 to $932 \mathrm{~kg} / \mathrm{m}^{3}$. When the result is compared with the EN14214, which is $860-900 \mathrm{~kg} / \mathrm{m}^{3}$ for biodiesel, the value is out of the range. The change in the density shows that the density of the biodiesel decreased with increasing molar ratio. This was probably due to a decrease in residual triglycerides. Moreover, the density of the biodiesel also decreased with increasing reaction temperature and catalyst amount. Therefore, further reduction on the density of the biodiesel is required to satisfy the international biodiesel standards.

Kinematic Viscosity: The viscosities of the biodiesel produced at lower temperature are higher than that of the corresponding experiments conducted with the same feed ratio at higher temperature. This is due to the effects of operating parameters that affect the transesterification reaction. On the other hand, the viscosity of the biodiesel increased slightly with decreases in reaction temperature.

Increase in molar ratio decreases the viscosity to some extent. This is probably because of the free area created for the triglycerides to convert to biodiesel as the molar ratio increased. However, as the molar ratio increases it inhabits the contact between the triglycerides and the catalyst. Hence, no change in viscosity is observed when excess molar ratio was used. Viscosity decreased up to optimal catalyst concentration then it was almost constant.

Transesterification reaction is responsible for minimizing the viscosity of vegetable oil in order to apply it as a fuel for engines yet it is significantly affected by temperature. This experimental result shows a viscosity of (12.5 to 20 $\left.\mathrm{mm}^{2} / \mathrm{sec}\right)$ which is out of both the ASTM $\left(1.9\right.$ to $\left.6 \mathrm{~mm}^{2} / \mathrm{sec}\right)$ and EN14214 (3.5 to $\left.5 \mathrm{~mm}^{2} / \mathrm{sec}\right)$ range for the requirement of biodiesel viscosity.

According to the results, it has been determined that pure $\mathrm{RC}$ biodiesel usage can cause problems in the injection system because of its high viscosity. In order to solve the viscosity problem it can be suggested that RC biodiesel may use a mixture of others either diesel or biodiesels. Therefore, in this paper further reduction of viscosity is done by blending with diesel fuel, which is the best solution for RC biodiesel usage in compression ignition engines.

Acid Value: The Acid value of the biodiesel was found to be in the range of 0.324 to $0.784 \mathrm{mgKOH} / \mathrm{g}$ and 0.567 $\mathrm{mgKOH} / \mathrm{g}$ at optimum conditions. The result indicates that the acid value of the oil $(1.86 \mathrm{mgKOH} / \mathrm{g})$ decreased significantly after transesterification reaction. Furthermore, higher acid value resulted in low yield of biodiesel. Acid value affects storage ability of biodiesel by Contact with air and water, which is the major factors affecting storage stability. Oxidation is usually accompanied by an increase in the acid value and viscosity of the fuel. In the presence of water, the ester can hydrolyze to long-chain FFA, which also causes the acid value to increase. The castor bean oil biodiesel has acid values within the standard specification limit of max 0.8 in ASTM D664.

Heating Value: The heating value of biodiesel depends on the composition of the fuel. Since all the oils have very nearly the same carbon, hydrogen and oxygen contents, the gross and net heating values of each fuel per unit mass will be close to each other. Biodiesel has lower energy content (lower heating value) than conventional diesel fuel. The result obtained $(40.5 \mathrm{MJ} / \mathrm{kg})$ is nearly the in the range of ASTMD6751 for diesel oil.

Iodine value: All of the measured IVs value falls in the En14124 standard. Higher IV indicates a higher quantity of double bonds in the sample and greater potential to polymerize in engine and hence lesser stability. The process of transesterification reduces the iodine value to a small extent. The EN14214 requirement is a maximum of 120 where as the result shows a maximum value of $86 \mathrm{I}_{2} / 100 \mathrm{I}_{2}$.

Cetane Number: Although the viscosity and the density of RC biodiesel were noted to be greater than that of diesel fuel, the Cetane number was found in the range of EN 14214. Cetane number is known as a measurement of the combustion quality of diesel fuel. It has been observed that Ricinus Communis biodiesel has a higher Cetane number, which causes shorter ignition delays, and thus, higher efficiency in engine. $\mathrm{CN}$ was determined using empirical formula and obtained an average of 57.11 for nine selected samples based on their higher percentage of FAME (>90\%) and 57.7 at optimization condition. The results showed that most of them have increased the $\mathrm{CN}$ within the permissible minimum limit. In general, diesel engines will operate on fuels with $\mathrm{CN}>47$ (ASTM D613).

Flash Point: Equations were developed for the calculation of the Higher Heating Value of vegetable oils and biodiesel from their viscosity $(v)$, density $(\rho)$ and flash point (FP) [9]. The FP was determined and the values are ranged from 131.2 to $135.0^{\circ} \mathrm{C}$. Hence, the $\mathrm{FP}$ of the castor bean oil biodiesel lies within the ASTM6751 $\left(>130^{\circ} \mathrm{C}\right)$ and EN14214 $\left(>101^{\circ} \mathrm{C}\right)$ permissible range.

\subsection{Determination of Diesel and Biodiesel Blending Proportion}

When biodiesel is blended with petro diesel, the concentration of biodiesel is always written as BXX. The 
' $\mathrm{XX}$ ' refers to the percentage volume of Biodiesel. For example, pure $100 \%$ biodiesel will be named as B100 and $\mathrm{B} 20$ is $20 \%$ Biodiesel and $80 \%$ petroleum diesel. Biodiesel can be used as B100 (neat). However neat biodiesel; because of having a narrow range of boiling points, slightly higher viscosity and density requires blending with petroleum diesel. Hence, blends with a petroleum diesel, at different proportions as B5, B10, \& B20 were used in different literatures. As a result, Cloud point and pour point are adjusted by blending. Blending up to $5 \%$ is also useful for lubricating purpose [15].

In this study, the properties of $\mathrm{B} 100$ and its B5, B10 ,B15, $\mathrm{B} 20, \mathrm{~B} 25, \mathrm{~B} 30, \mathrm{~B} 35, \mathrm{~B} 40$, and B45 mixtures were tested and compared to those of petroleum diesel and acceptable value is obtained within the specified for biodiesel in the ASTM D 6751 standard (with the exception of viscosity and density for B100). The results obtained are shown in Table3.6. It was found that viscosity was higher as the proportion of biodiesel in the mixtures increased. However, this event does not affect the atomization characteristics.

Table 3.6. Mixing proportion of diesel fuel and castor bean biodiesel

\begin{tabular}{|c|c|c|c|c|c|c|c|c|c|c|c|c|c|}
\hline Properties & Units & Diesel & B5 & B10 & B15 & B20 & B25 & B30 & B35 & B40 & B45 & B50 & B100 \\
\hline SG & - & 0.835 & 0.84 & 0.843 & 0.845 & 0.847 & 0.853 & 0.862 & 0.865 & 0.869 & 0.876 & 0.88 & 0.920 \\
\hline Density & $\mathrm{Kg} / \mathrm{m} 3$ & 835 & 840 & 843 & 845 & 847 & 853 & 862 & 865 & 869 & 876 & 880 & 920 \\
\hline viscosity & $\mathrm{mm}^{2} / \mathrm{s}$ & 3.81 & 3.87 & 3.98 & 4.00 & 4.38 & 4.89 & 5.50 & 5.87 & 5.98 & 6.05 & 7.54 & 12.5 \\
\hline
\end{tabular}

\section{Conclusions}

Based on the forgoing discussion, the conclusions of this study are summarized as follows:

* RC oil can be used as a biodiesel raw material with its high oil content and its non-edible characteristics.

\& Castor oil has very high kinematic viscosity and density, which was reduced by using high molar ratio during transesterification but still needed to be blended with diesel fuel to bring it to the limits for biodiesel.

$\$$ Of all the variables studied, the interaction between Methanol to oil ratio\& amount of catalyst had more influence on the yield of fatty acid methyl ester.

* The ester yield obtained from the transesterification process ranged from 46 to $92.5 \%$.

\& The optimum FAME yield of $94.5 \%$ was obtained at a catalyst concentration of $1.22 \mathrm{wt} \%$, methanol to oil molar ratio of $8.10: 1$ and Reaction temperature of $59.89^{\circ} \mathrm{C}$ at a reaction time of $2 \mathrm{hr}$ and $600 \mathrm{rpm}$

* HHV of castor biodiesel is slightly lower than that of diesel but has a higher calculated Cetane number.

* In this study, pure RC biodiesel usage can cause problems in injection system because of its high viscosity and density. Therefore, further reducing the viscosity and density of biodiesel is performed by blending with diesels oil up to B45 to use as alternative fuel for diesel oil in the existing conventional diesel engine.

\section{References}

[1] Demirbas A., (2003), Biodiesel fuels from vegetable oils via catalytic and non-catalytic supercritical alcohol transesterification and other methods: Energy Converse Manag.44, 2093-2109.

[2] Emission Standards, European Union. Cars and light trucks [online]. Available from: $\mathrm{http} / /$ www.dieselnet.com/standards/eu/ld.php [Accessed
2008].

[3] Lapuerta M., Armas O., and Rodriguez-Fernandez J., Effect of biodiesel fuels on diesel emissions: Progress in Energy and Combustion Science, 34 (2008) 198-223.

[4] Agarwal and Das, (2001), Agarwal, A.K., and L.M. Das., (2001), Biodiesel development and characterization for use as a fuel in compression ignition engines, Journal of Engineering for Gas, Turbines and Power 123: 440-447.

[5] Mulugetta Y., (2008), Evaluating the economics of biodiesel in Africa. Renew Sust Energy Rev., 13, 1592-15989.

[6] Fangrui, M., Milford A. Hanna, "'biodiesel Production: A review”, Bioresource Technology (1999), vol. 70, p. 1-15.3.

[7] Freedman B., Pryde E.H., Mounts T.L., (1984). Variables affecting the yields of fatty esters from transesterified vegetable oils: J Am Oil Chem Soc 61:1638-1984.

[8] Canoira, L., Galean, J.G., Alcantara, R., Lapuerta, M., Contreras, R.Y. (2010), Fatty acid methyl esters (FAMEs) from castor oil: Production process assessment and synergistic effects in its properties. Renewable Energy, vol. 35 , p. 208-217.

[9] Ayhan Demirbas, Biodiesel: A Realistic Fuel Alternative for Diesel Engines, Energy Technology Sila Science and Energy Trabzon Turkey, Springer, (2008).

[10] Jeong, G. T., Kim, D. H., \& Park, D. H. (2007), Applied Biochemistry and Biotechnology, 136-140, 583-594. Doi: 10.1007/s12010-007-9081.

[11] Akpan, U. G., Jimoh A.and Mohammed, A. D., (2006). Extraction, Characterization and Modification of Castor Seed Oil, Leonardo Journal of Science

[12] Salunke D. K., Desai B. B., Post-harvest Biotechnology of Oil Seeds, CRC Press, p. 161-170, 1941

[13] Lew Kowitseh J. I., Chemical Technology and Analysis of oils, Vol. 2: Fats and waxes, Macmillan, (1909)

[14] Marter A. D., Castor: Markets, Utilization and Prospects, Tropical Product Institute, G152, p. 55-78, 1981 and Weise E. A., Oil seed crops, Tropical Agriculture Series, p. 31-53, Longman, 1983 
[15] Ayhan Demirbas. 2008. Relationships derived from physical properties of vegetable oil and biodiesel fuels. Fuel. 87: $1743-1748$

[16] Encinar, J. M.; Juan, F.; Gonzalez, J. F.; Rodriguez-Reinares, A., (2005), Biodiesel from used frying oil: Variables affecting the yields and characteristics of the biodiesel. Ind. Eng. Chem.Res, 44 (15), 5491-5499.

[17] Silva, N. D. L. D., Maciel, M. R. W. M., Batistella, C. B., \& Filho, R. M. (2006). Applied Biochemistry \& Biotechnology, 129-132,405-414. Doi: 10.1385/ABAB: 130:1:405. 